\title{
O PAPEL DE INVESTIDORES-ANJOS EM EMPRESAS INVESTIDAS: UM ESTUDO EXPLORATÓRIO COM EMPRESAS DO ESTADO DO RIO DE JANEIRO
}

\section{THE ROLE OF INVESTORS-ANGELS IN INVESTED COMPANIES: AN EXPLORATORY STUDY WITH COMPANIES IN THE STATE OF RIO DE JANEIRO}

\author{
Giovanni Evangelista de Barros \\ rodrigo.dill@uffs.edu.br \\ Universidade Federal Fluminense - Niterói - RJ \\ Favio Akiyoshi Toda \\ favio.toda@gmail.com \\ Universidade Federal Fluminense - Niterói - RJ \\ Américo da Costa Ramos Filho \\ americoramos@id.uff.br \\ Universidade Federal Fluminense - Niterói - RJ
}

Recebido em 29.11.2017. Aprovado em 20.12.2017

Avaliado pelo sistema double blind review

\section{Resumo}

Este trabalho tem como objetivo principal avaliar a participação de investidores-anjos junto às empresas em que investiram, identificando as competências e os recursos que os mesmos possuem e que os permitem contribuir com o desenvolvimento do negócio. Neste sentido, este estudo busca contribuir adicionando a literatura do assunto mais informações à respeito do valor que os investidores-anjos podem agregar às empresas que fazem parte de seu portfólio. Para obter estas informações foram realizadas entrevistas semiestruturadas com sócios e empreendedores de empresas do Estado do Rio de Janeiro que receberam investimento-anjo em algum momento de sua trajetória. Com os resultados obtidos observou-se que os investidores contribuíram de forma mais significativa com o suporte financeiro, com a atuação e a disponibilidade de seu conhecimento técnico e, de forma mais modesta com o networking.

Palavras-chaves: Investimento-anjo. Participação. Empresas investidas.

\begin{abstract}
This paper aims to evaluate the role of angel investors in the companies in which they have invested, identifying their skills and resources and how they usually collaborate with the development of the business. Thus, the paper attempt to contribute with the literature by adding more insights about the value that the angel investors can add to their portfolio companies. Therefore, we conducted semi-structured interviews with angel investors and entrepreneurs from companies located in the State of Rio de Janeiro. After analyzing the results, we observed that angel investors contributed in a more significant way with their financial support, technical and management knowledge and more modestly with their networking.
\end{abstract}

Keywords: Angel investment. Contribution. Invested companies. 


\section{Introdução}

Em busca do crescimento econômico sustentável, alguns países emergentes, dentre eles o Brasil, passaram a estimular a inovação tecnológica e a criação de novos negócios, acreditando que este seria um meio de promover o desenvolvimento socioeconômico (BOTELHO, DIDIER E RODRIGUEZ, 2006).

A adoção desta estratégia exige a formação de um ambiente de negócios mais favorável aos novos empreendimentos, com a oferta de fontes de financiamento e a criação de mecanismos de suporte as empresas inovadoras. Por esta necessidade, temas de relevância como o empreendedorismo e 0 financiamento da inovação ganharam mais espaço na agenda de políticas públicas e maior notoriedade no meio acadêmico.

Sabe-se que a fonte inicial de recursos para qualquer empresa é o capital aplicado pelas partes interessadas na criação do negócio, pessoas físicas e jurídicas. Este capital também é chamado de capital próprio e é entendido de forma mais ampla como os recursos empregados pelo empreendedor e por seus sócios no novo negócio.

Ocorre que, durante a criação destes novos negócios, uma boa parte dos empreendedores não dispõem de capital próprio ou não conseguem apoio estatal para implementar os seus projetos. Nestas circunstâncias, o acesso ao capital de terceiros, que podem ser investidores individuais ou investidores institucionais, pode suprir a necessidade dos empreendedores que buscam financiamento para seus negócios.

Estes investidores oferecem os recursos financeiros e o apoio necessário para o desenvolvimento destes negócios, nos quais os empreendedores, por possuírem poucos ativos reais e não poderem usá-los como garantia em um empréstimo, encontram grandes dificuldades na obtenção de financiamento.

Este estudo tem como ponto de partida o interesse pela pesquisa em um tema ainda pouco aprofundado no contexto brasileiro, o venture capital, que é hoje, uma das principais fontes de financiamento de empresas inovadoras e pode ser traduzido como capital de risco ou capital empreendedor, como preferem alguns. Este trabalho aborda em especial uma das modalidades de investimento que usualmente financiam empresas inovadoras e que compõe o mercado de venture capital, o investidor-anjo, também conhecido como investidor informal.

O investidor-anjo pode ser descrito como um investidor individual e independente, que dispõe de um patrimônio que o permite investir em empresas que julgam inovadoras e que apresentem potencial de crescimento. Estes investidores realizam uma troca simples, realizam o aporte de capital e passam a deter um percentual de participação na empresa em questão.

Este aporte de capital é, na maior parte das vezes, o motivo principal por trás da realização do investimento, no entanto, a relação dos investidores-anjos com as empresas investidas pode ir além do suporte financeiro. Estes investidores podem deixar de lado o papel de meros espectadores e se envolver nas atividades da empresa, agregando valor e contribuindo para o seu crescimento.

Por mais que os investidores-anjos, assim como outras modalidades de investimentos, possam participar e monitorar ativamente a gestão e o desempenho das empresas que fazer parte de seu portfólio, observa-se que ainda existem poucos estudos relativos à influência destes investidores nas empresas investidas no Brasil, assim como existem poucos estudos sobre as características que levariam estes investidores a participar de forma mais ativa na gestão destas empresas.

Este estudo busca suprir, ou pelo menos contribuir com mais informações à respeito deste tema e responder à seguinte pergunta: "De que forma os investidores-anjos influenciam ou afetam as empresas que fazem parte de seu portfólio?", ou seja, esta pesquisa tem como objetivo central avaliar a participação de investidores-anjos junto às empresas de seu portfólio, identificando as competências e os recursos que os mesmos possuem e que os permitem contribuir com o seu desenvolvimento.

Consideram-se objetivos específicos desta pesquisa: 
1. Observar se os investidores-anjos agregam uma rede de contatos às empresas de seu portfólio e, de que forma isto ocorre;

2. Identificar como o investimento-anjo oferece o suporte necessário ao momento vivido pelas empresas, e como abre portas para novas rodadas de investimentos;

3. Examinar o impacto da presença dos investidores-anjos na governança e nos processos das empresas investidas;

4. Avaliar se os investidores-anjos influenciam ou não na gestão dos recursos e na eficiência operacional das empresas investidas.

Como forma de delimitar o objeto de estudo e até mesmo facilitar a realização desta pesquisa, optou-se por restringir este trabalho a uma análise com base em empresas investidas que tiveram sua origem no Estado do Rio de Janeiro.

\section{Investimento-anjo}

O termo "angel" teve origem nos Estados Unidos, no início do século XX e, a princípio, mantinha relação com os investidores que faziam investimentos de risco para apoiar as produções teatrais da Broadway (PRESTON, 2004). Hoje em dia o termo é utilizado para designar uma pessoa com elevada riqueza líquida, que na maior parte das vezes é também um investidor qualificado (BOTELHO, DIDIER \& RODRIGUEZ, 2006), que de acordo com a SEC (Securities and Exchange Commission), agência regulatória americana, é um indivíduo que possui riqueza líquida superior à US\$ 1 milhão ou que ganhe mais de US\$200,000 por ano.

Fili e Grünber (2014) descrevem os anjos como investidores individuais (Pessoa Física), donos de um elevado patrimônio líquido, que atuam por conta própria ou através de sindicatos e associações, investindo capital próprio diretamente em negócios que consideram inovadores, com elevado potencial de crescimento e rentabilidade.

Estes indivíduos são, na maior parte das vezes, os criadores de suas próprias fortunas. Em geral, eles foram ou ainda são empreendedores e executivos de sucesso, atuando tanto na área da gestão de negócios como nas áreas mais técnicas (FREITAS E CALVOSA, 2008).

Os investidores-anjos geralmente solicitam uma participação societária em troca de capital e, em alguns casos, dedicação ao negócio. O retorno que estes investidores pretendem obter é o resultado da valorização da empresa em que investiram, na medida em que esta se desenvolve, cresce e apresenta resultados financeiros sólidos.

Segundo Mason e Harrison (2000), a comunidade de investidores-anjos representa a mais antiga e maior fonte de recursos de capital para os estágios iniciais de um empreendimento e, alguns estudos já realizados sugerem que o montante de investimentos realizados por investidores-anjos é superior ao montante de investimentos realizados por investidores institucionais em países como os EUA, o Reino Unido e a Suécia.

Dentre todos os países, os Estados Unidos apresenta provavelmente o mercado informal de venture capital mais desenvolvido. De acordo com o estudo realizado pela Universidade de New Hampshire (SOHL, 2007) o mercado de investimento-anjo nos EUA é de US\$ 25,6 bilhões, o que o torna do mesmo tamanho do mercado formal de venture capital, composto pelos fundos de venture capital. Este estudo aponta que hoje, o investidor-anjo é a mais importante fonte de financiamento para negócios e empresas emergentes no país, havendo cerca de 400 mil investidores-anjos em atividade.

Há bastante tempo os investidores-anjos vêm exercendo um papel importante como fonte de financiamento de empresas inovadoras, principalmente daquelas que se encontram em estágio inicial. Algumas empresas, hoje reconhecidas no cenário global, contaram com o investimento-anjo no início de sua trajetória, dentre elas destacamos Google, FedEdx, Facebook, Apple e Intel. 
Estes investidores geralmente realizam poucos investimentos e enxergam as empresas em que investem como uma oportunidade de se envolver em projetos empreendedores, ao mesmo tempo em que diversificam os seus investimentos. Para as empresas investidas, o investimento-anjo atua, na maior parte das vezes, como um trampolim para novas rodadas de investimento. Sua aplicação é efetuada principalmente nos estágios iniciais, com o objetivo de levar a empresa a um crescimento sustentado, capaz de torná-la atrativa aos olhos de investidores institucionais (BOTELHO, DIDIER \& RODRIGUEZ, 2006). Muitas vezes, 0 investimento-anjo é interpretado como um credenciamento para que as empresas venham a obter investimentos de fundos de venture capital (MADILL, HAINES \& RIDING, 2005).

De acordo com Lee \& Correia (2004), as etapas que fazem parte do ciclo de vida de uma empresa exigem diferentes valores de aportes e condições de financiamento. No meio empreendedor é comum ver investidores-anjos e fundos de investimento em venture capital segmentando a sua atuação, isto é, optando por investir em empresas em determinado estágio de crescimento.

A Figura 1 apresenta o ciclo de crescimento de novas empresas e as principais fontes de recursos utilizadas em cada uma de suas etapas.

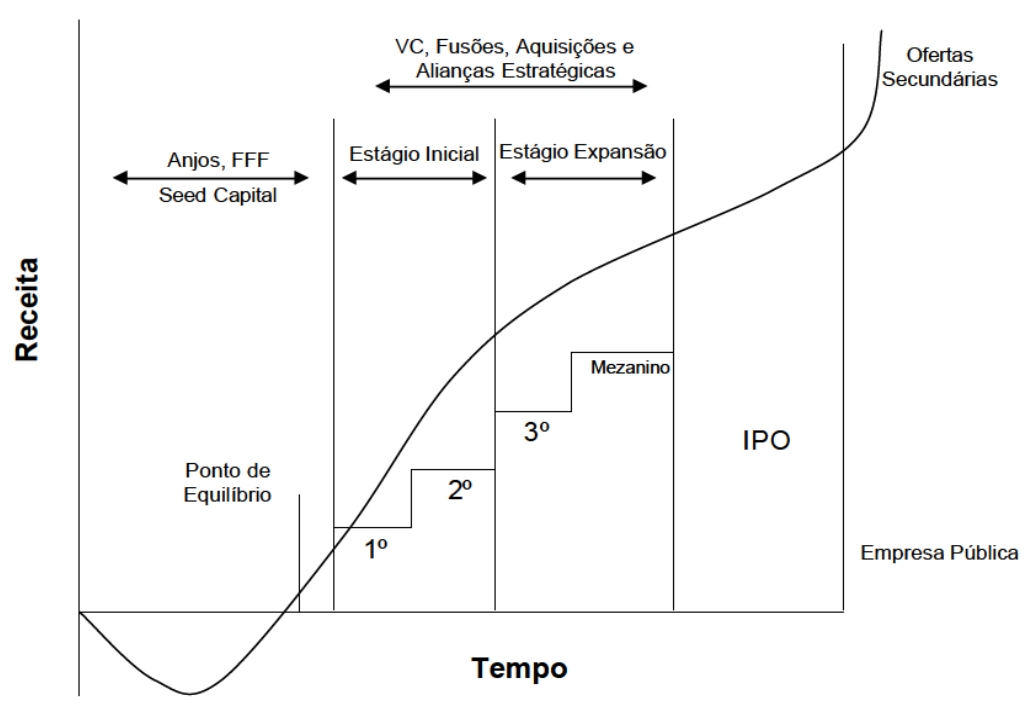

Figura 1 - 0 ciclo de crescimento de novas empresas e as fontes de financiamento.

Fonte: Cardullo (1999), citado em Lee \& Correa (2004).

Os investidores-anjos optam, na maioria das vezes, por investir no estágio inicial da organização, que é também conhecido como "seed capital" (LIMA, 2006). Este estágio é marcado por experimentações com a tecnologia que será utilizada pela empresa, pela dúvida em relação ao futuro e ao desenvolvimento do negócio e pelo enfrentamento às barreiras de entrada impostas pelo mercado (CARIS, 2006).

O investidor-anjo exerce, portanto um papel central no desenvolvimento de pequenas empresas inovadoras, pois atua diretamente no gap financeiro que existe entre o capital dos empreendedores e fundadores e os fundos de venture capital, que preferem investir em empresas que se encontram na etapa de estágio inicial.

\section{Investimento-anjo no Brasil}

Segundo Spina (2011), no Brasil, o número de investimentos realizados por anjos aumentou consideravelmente a partir da década de 90 , porém estes investimentos sempre ocorreram de forma passiva, ou seja, os empreendedores corriam atrás e, através de sua rede de contatos, conseguiam encontrar investidores-anjos dispostos a investir em seus negócios. Ainda hoje, a maioria dos investimentos ocorre desta forma, no entanto, já é possível afirmar que estes investidores estão se profissionalizando e se tornando cada vez mais ativos na busca por oportunidades de investimento.

De acordo com o $2^{\circ}$ Censo Brasileiro da Indústria de Private Equity e Venture Capital, estudo realizado pela Fundação Getúlio Vargas no ano de 2011, uma tendência identificada no mercado brasileiro em especial é ISSN 2318-9231 
a formação de clusters e de redes de investidores-anjos. Em alguns casos, estes investidores formam redes de contato e se reúnem em associações com o intuito de localizar as empresas com o maior potencial de desenvolvimento.

Estas associações costumam operar como uma espécie de "agência de encontros", abrindo as portas para que os empreendedores apresentem as suas ideias de negócio para um maior número de investidores, 0 que proporciona a comunidade de investidores-anjos um espaço de discussão e de descoberta das melhores oportunidades de investimento.

As associações podem também preencher uma lacuna importante no financiamento de empresas inovadoras, tendo em vista que, muitas vezes os empreendedores buscam quantias que não são providas nem por fundos de venture capital e nem por investidores-anjos que atuam sozinhos. Neste caso, a atuação dos investidores-anjos em conjunto poderia reunir o capital necessário para os negócios e preencher este gap financeiro.

Vale ressaltar que, embora estas organizações reúnam investidores com o mesmo propósito, cada um de seus associados e podem decidir individualmente se desejam ou não entrar em uma oportunidade de investimento.

Atualmente, no Brasil, existem diversas associações de investidores-anjos, são elas: a Gávea Angels (a mais antiga, criada em 2002), a São Paulo Anjos, a Bahia Anjos e a Floripa Angels. A Figura 2, extraída deste estudo, expõe o montante de capital comprometido nas associações de investidores-anjos no Brasil. Como este estudo foi realizado no ano de 2011 é bem provável que os valores expostos tenham crescido nos últimos anos, tendo em vista o crescimento do mercado de venture capital no país.

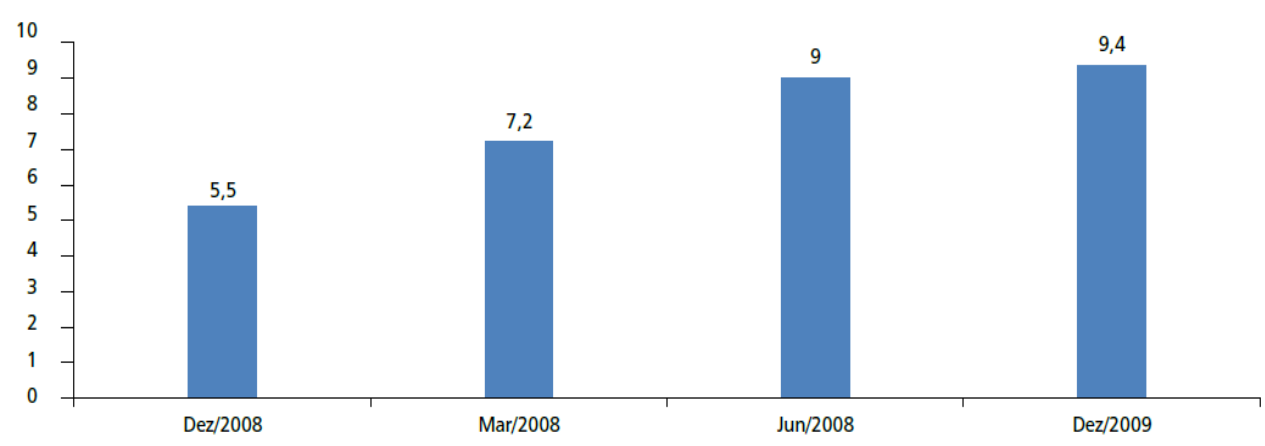

Figura 2 - Montante de capital comprometido em associações de investidores-anjos no Brasil (em US\$ milhões).

Fonte: Base de Dados GVcepe - Fundação Getulio Vargas.

Com 0 intuito de traçar o perfil dos investidores-anjos brasileiros, até o momento destacam-se duas pesquisas, uma delas fora realizada em meio ao Projeto New Venture Financing - NVF e a outra encomendada recentemente pela rede Anjos do Brasil.

A primeira destas pesquisas, realizada no âmbito do Projeto NVF, ocorreu entre os anos de 1999 e 2002 e contou com o levantamento do perfil de investidores-anjos em quatro dos principais estados brasileiros: Minas Gerais, Rio de Janeiro, Rio Grande do Sul e São Paulo. A outra pesquisa, encomendada pela rede Anjos do Brasil no ano de 2014 e apresentada durante o II Congresso de Investimento Anjo, é a mais recente e pode ser considerada a mais representativa, uma vez que contou com uma base de 6.300 investidoresanjos, espalhados pelos estados do país.

Os quadros logo abaixo apresentam os resultados obtidos nestas pesquisas. 


\begin{tabular}{|c|c|}
\hline \multicolumn{2}{|l|}{ Dados demográficos } \\
\hline Idade & $\begin{array}{l}\text { A idade média é de } 43 \text { anos, sendo que a maior parte } \\
\text { destes tem entre } 30 \text { e } 50 \text { anos. }\end{array}$ \\
\hline Sexo & $94 \%$ dos investidores-anjos é do sexo masculino. \\
\hline Educação & $\begin{array}{l}\text { Pós-Graduação (46\%) } \\
\text { Graduação (43\%) } \\
\text { Doutorado (3\%) }\end{array}$ \\
\hline \multicolumn{2}{|c|}{ Aspectos econômico-financeiros dos Investidores-Anjos } \\
\hline $\begin{array}{l}\text { Montantes médio que estariam } \\
\text { dispostos a investir em cada } \\
\text { negócio }\end{array}$ & $\begin{array}{l}73 \% \text { preferem investir um montante máximo de até } \mathrm{R} \$ \\
100.000,00 \text {. }\end{array}$ \\
\hline $\begin{array}{l}\text { Percentagem do patrimônio } \\
\text { investido }\end{array}$ & $57 \%$ investiram utilizando até $6 \%$ de seus ativos. \\
\hline $\begin{array}{l}\text { Quantidade de investimentos } \\
\text { que realizaram no período de } \\
\text { um ano }\end{array}$ & $\begin{array}{l}\text { Vinte e seis anjos ( } 81 \% \text { da amostra) realizaram } 61 \\
\text { investimentos no período de um ano, sendo que a maioria } \\
\text { investiu em apenas uma empresa. }\end{array}$ \\
\hline $\begin{array}{l}\text { Taxa média anual de retorno } \\
\text { esperado }\end{array}$ & $\begin{array}{l}50 \% \text { dos investidores almejam uma taxa média anual de } \\
\text { retorno que vá de } 12 \% \text { a } 21,5 \% \text {. }\end{array}$ \\
\hline $\begin{array}{l}\text { Tempo esperado de retorno do } \\
\text { investimento }\end{array}$ & $\begin{array}{l}37 \% \text { dos investidores visam um retorno do investimento } \\
\text { no período de } 4 \text { à } 6 \text { anos. }\end{array}$ \\
\hline Participação desejada & $\begin{array}{l}95 \% \text { dos investidores preferem deter uma participação } \\
\text { societária que vá de } 12 \% \text { à } 15 \% \text { da empresa. }\end{array}$ \\
\hline Motivação para investir & $\begin{array}{l}\text { 1. Possibilidade de obter maior rentabilidade se } \\
\text { comparado a outros investimentos; } \\
\text { 2. Confiança no empreendedor e na equipe de gestão; } \\
\text { 3. Satisfação pessoal. }\end{array}$ \\
\hline
\end{tabular}

Quadro 1 - Perfil do investidor-anjo no Brasil segundo o Projeto NVF.

Fonte: adaptado de Botelho et al., (2006).

Idade

A idade média dos investidores anjo no País é de 43 anos, sendo que a maioria (48\%) se encontram abaixo dos 39 anos. 


\begin{tabular}{|c|c|}
\hline Sexo & $95 \%$ dos investidores-anjos é do sexo masculino. \\
\hline Atividade principal & $\begin{array}{l}\text { Empresários (49\%) } \\
\text { Executivos }(23 \%) \\
\text { Investidores e gestores (11\%) } \\
\text { Profissionais liberais }(9 \%)\end{array}$ \\
\hline Dedicação & $\begin{array}{l}\text { Os investidores investem cerca de } 16,4 \% \text { do seu tempo } \\
\text { total disponível. }\end{array}$ \\
\hline $\begin{array}{l}\text { Quantidade de investimentos } \\
\text { realizados }\end{array}$ & A média de investimentos já realizados é de 2,1. \\
\hline Montante investido & $\begin{array}{l}\text { Cada investidor aplica em média } \mathrm{R} \$ 687.000,00 \text { em } \\
\text { startups. }\end{array}$ \\
\hline Interesses & $\begin{array}{l}\text { Área de TI }(60 \%) \\
\text { Aplicativos }(56 \%) \\
\text { Educação }(54 \%) \\
\text { Saúde /Biotecnologia }(48 \%) \\
\text { E-Commerce }(40 \%) \\
\text { Entretenimento }(21 \%) \\
\text { Outras áreas }(11 \%)\end{array}$ \\
\hline Projeto ideal & $\begin{array}{l}\text { Boa qualidade do projeto }(61 \%) \\
\text { Perspectiva de saída/retorno (50\%) } \\
\text { Proteção ao seu patrimônio (45\%) } \\
\text { Retorno fiscal ou tributário }(15 \%)\end{array}$ \\
\hline Potencial de investimento & $\begin{array}{l}\text { Ao final de } 2013 \text {, foram contabilizados } 6.450 \\
\text { investidores anjos no País, com uma previsão de } \\
\text { crescimento de } 20 \% \text { ao ano. Todos esses investidores } \\
\text { somam uma intenção de investimentos, para o cenário } \\
2014 / 2015 \text {, de } R \$ 339 \text { mil, resultando num total de } R \$ 2,6 \\
\text { bilhões investidos em startups nesse mesmo período. }\end{array}$ \\
\hline
\end{tabular}

Quadro 2 - Perfil do investidor-anjo no Brasil segundo a rede Anjos do Brasil.

Fonte: http://www.anjosdobrasil.net/

Os resultados trazidos por estas pesquisas revelam que os investidores-anjos brasileiros são, em maioria absoluta, indivíduos do sexo masculino e possuem uma idade média de 43 anos.

As pesquisas apontam que estes investidores geralmente são graduados ou pós-graduados (91\%) e exercem principalmente as funções de empresário (49\%), executivo (23\%) e investidor/gestor (11\%), atividades profissionais com as quais mantém contato com o mercado, com a gestão e a criação de novos 
negócios.

As informações obtidas a respeito da formação e da atuação profissional dos investidores revelam uma característica peculiar aos investidores-anjos brasileiros, os mesmos não possuem significativa base tecnológica, mas sim, elevados conceitos na área gerencial, administrativa e jurídica, haja visto o exercício de sua atividade profissional nestas áreas.

\section{A atuação dos investidores-anjos junto a empresas investidas}

De acordo com Botelho, Didier e Rodriguez (2006), os investidores-anjos buscam principalmente a obtenção de um retorno financeiro significativo e compatível com o risco assumido, no entanto, não investem somente por este motivo. Estes investidores, em determinados casos, podem estar motivados pela possibilidade de participar e de se envolver em uma ação empreendedora ou até mesmo de proporcionar um retorno à sociedade.

Por realizarem uma menor quantidade de investimentos, estes investidores geralmente dispõem de mais tempo e podem acompanhar de perto as empresas nas quais investiram, participando de forma mais ativa de suas atividades (MASON E HARRISON, 2002). Grande parte destes investidores assumem posições no conselho de administração das empresas nas quais detém participação, podendo atuar como consultores ou até mesmo empregados, caso haja a necessidade ou o convite para integrar a equipe de gestão da empresa investida.

Macht e Weatherston (2011) destacam que o envolvimento destes investidores nas empresas investidas não depende exclusivamente de sua vontade e nem sempre é bem visto pelos empreendedores, que podem preferir um envolvimento menor por parte destes investidores. De Noble (2001) aponta que este envolvimento, a depender das circunstâncias e das características do investidor, pode se mostrar indiscreto e prejudicial ao desenvolvimento das atividades do negócio.

Para fins de classificação o grau de envolvimento destes investidores com as empresas investidas é dividido em ativo e passivo. Segundo Mason (2002), investidores ativos são aqueles que aproveitam sua experiência para monitorar, gerenciar e controlar seus investimentos, em uma abordagem que ficou conhecida como "hands on management". Os investidores passivos por sua vez, preferem oferecer apenas o suporte financeiro ao negócio, ficando de fora do dia-a-dia da empresa.

Trabalhos como o de Harding e Cowling (2006) apontam que o envolvimento dos investidores-anjos com as empresas investidas vai muito além do suporte financeiro, estes investidores podem contribuir com sua experiência no campo da gestão de negócios, agregar às empresas uma rede de contatos, estimular 0 desenvolvimento de tecnologias e abrir as portas para novas rodadas de investimentos.

Kelly e Hay (2001) destacam que os investidores-anjos podem estar envolvidos em uma série de atividades do negócio, dentre as quais: colaboração durante o desenvolvimento das estratégias do negócio, participação no conselho de administração da empresa, ampliação da rede de contatos da empresa, acompanhamento dos indicadores financeiro e até mesmo com a aplicação das técnicas de coaching e mentoring junto ao empreendedor.

A atuação do investidor-anjo como coach ou mentor ocorre inclusive com grande frequência no meio empreendedor. Estes mesmos investidores-anjos, em alguma etapa de sua carreira foram empreendedores e, por possuírem maior experiência nesta área, buscam aconselhar os empreendedores mais jovens e passar alguns ensinamentos para que não cometam os mesmos erros que um dia cometeram.

Match (2011) afirma que até mesmo os investidores-anjos com menos experiência podem contribuir de forma positiva com a empresa, participando de atividades que não estejam necessariamente relacionadas com a operação do negócio ou a entrega do produto. Estes personagens poderiam contribuir de forma significativa ao atuar em atividades de apoio.

Ardichvilli et al. (2002) estudaram os diferentes tipos de recursos que os investidores-anjos poderiam oferecer às empresas de seu portfólio e, , separaram estes recursos em alguns grupos, de acordo com sua natureza. À princípio, os autores estabeleceram as seguintes categorias: capital humano, capital social, 
recursos físicos, capital organizacional e capital financeiro.

No quadro a seguir se encontram as descrições destas categorias.

\begin{tabular}{|l|l|}
\hline CATEGORIA & DESCRIÇÃO \\
\hline Capital humano & $\begin{array}{l}\text { Conhecimento, habilidades e experiências na área de } \\
\text { gestão, assim como na área de atuação da empresa. }\end{array}$ \\
\hline Capital social & $\begin{array}{l}\text { Estabelecimento e/ou ampliação de uma rede de } \\
\text { contatos favorável ao desenvolvimento do negócio. }\end{array}$ \\
\hline $\begin{array}{l}\text { Capital } \\
\text { organizacional }\end{array}$ & $\begin{array}{l}\text { Criação de uma cultura organizacional, estabelecimento } \\
\text { de uma base de dados, consolidação de processos e } \\
\text { registro de patentes. }\end{array}$ \\
\hline Recursos físicos & $\begin{array}{l}\text { Acréscimo de ativos tangíveis. Ex: bens, máquinas e } \\
\text { equipamentos úteis ao negócio. }\end{array}$ \\
\hline Capital financeiro & $\begin{array}{l}\text { Suporte financeiro oferecido à empresa no momento do } \\
\text { investimento e a habilidade para negociar novas } \\
\text { rodadas de investimento. }\end{array}$ \\
\hline
\end{tabular}

Quadro 3 - Categoria de recursos oferecidos por investidores-anjos segundo Ardichvilli et al. (2002). Fonte: adaptado de Ardichvilli et al. (2002).

\section{Metodologia}

Este trabalho se caracteriza como uma pesquisa qualitativa, de caráter exploratório, com dados coletados a partir da realização de entrevistas semiestruturadas com sócios de empresas que receberam investimentosanjos em algum momento de sua trajetória, sediadas no Estado do Rio de Janeiro.

Como ponto de partida para a coleta de informações, optou-se por entrar em contato com as principais incubadoras e aceleradoras do Estado do Rio de Janeiro, tendo em vista que estas entidades reúnem uma comunidade de empreendedores de base tecnológica e especialistas no assunto. Ao todo foram realizadas cinco entrevistas entre os meses de março e junho de 2015, através do aplicativo Skype, onde foram gravadas com o consenso dos entrevistados, transcritas, revisadas e interpretadas posteriormente.

A escolha pela realização de entrevistas semiestruturadas buscava conceder maior flexibilidade à coleta de dados, por apresentar caráter mais informal e por dar ao entrevistado maior liberdade para se aprofundar no tema, e expor suas considerações à respeito da participação dos investidores-anjos nas empresas.

0 roteiro semiestruturado utilizado foi estabelecido previamente e buscou abordar quatro pontos principais para debate com os entrevistados, a saber:

1. O acréscimo de uma rede de contatos favorável ao desenvolvimento do negócio;

2. O suporte financeiro ao momento atual e a expectativa em relação à novas rodadas de investimento no futuro;

3. O impacto destes investidores na governança das empresas investidas e em seus processos;

4. A participação destes investidores na gestão e sua influência no desempenho operacional das empresas.

Além disso, o roteiro abordava questões à respeito do perfil dos entrevistados e dos investidores e características da empresa investida, permitindo também que outros assuntos pudessem surgir para 
maiores esclarecimentos e ampliação do conhecimento sobre os objetivos definidos.

Os empreendedores que participaram das entrevistas estão à frente de empresas que atuam em diversas áreas. $O$ quadro 4, logo abaixo, expõe a área de atuação de cada uma das empresas que fizeram parte deste estudo.

\begin{tabular}{|l|l|}
\hline EMPRESA & ÁREA DE ATUAÇÃO \\
\hline Empresa A & Educação \\
\hline Empresa B & Logística \\
\hline Empresa C & Mídias \\
\hline Empresa D & E-Commerce \\
\hline Empresa E & Tecnologia da informação \\
\hline
\end{tabular}

Quadro 4 - Áreas de atuação das empresas entrevistadas.

Fonte: elaborado pelo autor.

\section{Apresentação e análise de resultados}

Nesta seção, para melhor compreensão, os resultados serão apresentados de acordo com os objetivos definidos pelo estudo e a ordem utilizada durante o roteiro.

\section{Ampliação da rede de contatos do negócio}

A partir das entrevistas realizadas, observou-se que os investidores contribuíram com a ampliação da rede de contatos da empresa, ainda que esta contribuição, em alguns casos, tenha sido modesta.

Em termos de networking, o entrevistado da empresa "A" afirma que foram poucos os contatos acrescentados ao negócio, uma contribuição bem tímida, no entanto, destaca a qualidade e a grandeza das parcerias estratégicas estabelecidas, com empresas como Natura, Coletivo Coca-Cola e Leroy Merlim.

$O$ entrevistado da empresa $B$ revela que o investidor-anjo intermediou a relação com alguns clientes nos primeiros meses após o fechamento do acordo, em um momento importante para a empresa.

"Na época ele trouxe 3 clientes para a empresa, 3 clientes com o seu networking e na sequência também trouxe o approach comercial, o approach de mercado."

O entrevistado da empresa $C$ citou que poucos foram os contatos acrescentados pelo investidor-anjo, destacando que o networking não era, naquela época, o objetivo principal.

"Poucos foram os contatos. Como eu falei a gente tava mais interessado no momento em uma pessoa que pudesse tocar a empresa com esta nova visão, que a gente tava imaginando de redirecionamento estratégico para os nossos serviços. Então, dizer que não trouxe nenhum contato não é verdade, mas pouco , não era o objetivo inicial não".

Segundo o entrevistado da empresa $D$, poucos foram os contatos acrescidos pelos investidores-anjos. Ele destacou uma parceria importante estabelecida com o Banco Bradesco por meio de seus investidores.

"O que eles ajudavam era na área mais high level, a parte mais estratégica, ir ou não para outros estados, parcerias estratégicas com grandes empresas e, aí sim, eles contribuíram. Nós fizemos uma parceria com o Bradesco, numa linha que o Bradesco tem chamada Bradesco Universitário, que são benefícios feitos para estudantes que usam o cartão do Bradesco Universitário, que foi feita uma intermediação via nossos investidores." 
De acordo com o entrevistado da empresa $E$, o investidor foi responsável pelo levantamento de alguns contatos, no entanto, ele destacou que a maior parte das parcerias foram estabelecidas em decorrência do seu próprio esforço e de seu sócio.

"O investidor trouxe alguns contatos sim, principalmente no início, logo que chegou, mas o networking da empresa foi feito por mim e por meu sócio, a gente que sempre correu atrás de clientes".

\section{Suporte financeiro}

Dentro deste tópico, pode-se perceber a importância do aporte de capital realizado pelos investidores. Em conformidade com 0 que fora apresentado por Caris (2006), os investimentos realizados estavam direcionados a consecução de alguns objetivos, como a consolidação do produto ofertado e a montagem de uma equipe de trabalho.

$O$ entrevistado da empresa A destacou que a maior contribuição proporcionada pelos investidores-anjos foi 0 aporte de capital, uma vez que a empresa passava por um momento importante e 0 aporte de capital permitiu o desenvolvimento do produto e o seu estabelecimento no segmento de atuação.

O entrevistado da empresa B acredita que do ponto de vista financeiro os investimentos atenderam as expectativas, possibilitando o ajuste de seu modelo de negócio, que na época sofrera algumas mudanças.

"O objetivo principal por trás do investimento era concluir o produto, ter verba para concluir o produto e colocar o modelo de negócio pra tracionar no mercado porque a gente estava saindo de uma linha de serviço pra começar a fazer uma oferta de produto de tecnologia. Então, pra isso, a gente precisava manter uma equipe mínima e ter dinheiro para pagar as contas, isso era o principal."

O entrevistado da empresa $\mathrm{C}$ revela que o aporte de capital ocorreu em um momento crítico para a empresa, que passava por um processo de redirecionamento do negócio.

"Bem, no nosso caso, a busca pelo investidor-anjo se deu motivada por um processo de redirecionamento do negócio. $O$ termo que se usa no meio do Empreendedorismo é pivot. A gente pivoteou a ideia inicial da empresa e com isso a gente precisava de um fôlego financeiro, que não era muito grande, mas que naquele momento era importante pra gente poder conseguir estruturar essa nova oferta da empresa pro mercado."

De acordo com o entrevistado da empresa $D$, o investimento foi importante para que, na época, alguns objetivos da empresa fossem alcançados.

"Por isso esses $\mathrm{R} \$ 600.000,00$ foram importante pra desenvolver o time inicial, contratar os primeiros funcionários e pra ter algum tipo de operação no estado do RJ E SP, que era o nosso interesse inicial".

$O$ entrevistado da empresa $E$ destacou como ponto positivo do investimento o aporte de capital, que considerou importante para o desenvolvimento do produto ofertado.

"O aporte de capital foi muito importante pra gente. Naquela época a gente tinha apenas uma ideia de produto, não tínhamos um produto. Com esse dinheiro a gente conseguiu terminar o nosso produto e iniciar as primeiras ações de marketing".

\section{Impacto na governança e nos processos da empresa}

A partir dos resultados obtidos vê-se que não há um reconhecimento explícito quanto ao impacto nos processos da empresa, exceto em relação à disponibilização de informações financeiras naturalmente exigidas pela aplicação de recursos dos investidores-anjos.

O entrevistado da empresa "A" afirma não ter identificado melhorias em termos de processos e de transparência com a chegada dos investidores. Segundo ele, a entrada dos novos sócios só reforçou a necessidade de alguns processos simples, como o acompanhamento dos indicadores de desempenho e os principais indicadores financeiros, algo que já era acompanhado antes.

"Hoje, os investidores acompanham os resultados financeiros da empresa periodicamente, de três em três 
meses e, através das reuniões, acompanham também o número de alunos matriculados, mas 0 acompanhamentos destas informações era realizado até mesmo antes da chegada dos anjos".

O entrevistado da empresa "B" ressaltou que, em meio ao investimento, a empresa se enquadrou como uma Sociedade Anônima, o que implicou na melhoria de alguns processos e no ganho de mais transparência.

"Olha, a gente fez, em 2014, com a entrada dos sócios, a entrada da empresa como S.A. Então esse é o primeiro ponto que a gente fez efetivamente. Segundo, com a obrigação de S.A. você tem no mínimo que fazer uma composição anual para aprovar as demonstrações contábeis e financeiras da empresa, uma GO, que seria anual. Isso trouxe muito mais transparência para a empresa".

Segundo o entrevistado da empresa "C", a chegada do investidor-anjo trouxe um pouco mais de transparência para o negócio, uma vez que, na função de administrador, ele passou a trabalhar de forma mais frequente com os indicadores de desempenho e com a elaboração e apresentação de relatórios financeiros ao demais sócios.

"Respondendo a sua pergunta, sim, a gente estabeleceu alguns critérios de desempenho, começamos a preparar relatórios financeiros e ele tinha a função de CEO de apresentar aos outros sócios e pra ele mesmo, então de certa forma a entrada do investidor trouxe um pouco mais de transparência aos processos da empresa, mas não foi nada muito significativo".

O entrevistado da empresa "D" acredita que, por participarem pouco da rotina da empresa, os investidores pouco influenciaram em seus processos, no entanto destacou como ponto positivo do investimento a mudança na postura dos próprios empreendedores.

"Para um empreendedor de primeira viagem, você ter um investimento, você começa a perceber que o negócio é sério, então você começa a se comprometer mais com a causa, você começa a ser mais profissional, você começa a ser reportar de uma maneira que não se reportava antes, porque você tem outras pessoas que acreditaram em você, isso é uma coisa legal."

O entrevistado da empresa "E" afirma que não houve nenhuma melhora neste aspecto. De acordo com ele, a empresa sempre manteve processos muito simples e, com a chegada dos investidores ele passou apenas a apresentar as informações financeiras.

"Posso dizer que mudou muito pouco. Na verdade, nada mudou. Nós sempre elaboramos relatórios, simples, é claro. A única diferença é que agora, eu apresento estes relatórios ao meu sócio e aos demais investidores".

\section{A atuação na gestão das empresas}

A atuação dos investidores nas empresas mostrou-se limitada, seja pela preferência dos próprios investidores ou seja pela delimitação por parte dos sócios. No entanto, em empresas que não apresentavam uma competência gerencial reconhecida, a atuação foi mais que uma assessoria estratégica, em situações nas quais os investidores-anjos assumiram a administração das empresas por um determinado tempo.

Segundo o entrevistado da empresa "A", o nível de participação dos investidores no negócio sempre foi um item da pauta das negociações que antecederam o investimento. A liberdade e a autonomia para operacionalizar o negócio foram condições estabelecidas pelos próprios sócios. Hoje, estes mesmos investidores acompanham periodicamente os resultados obtidos pela empresa, no entanto, não participam de sua operação.

O entrevistado da empresa "B" destacou a contribuição do investidor-anjo com o seu conhecimento na área de gestão, em especial a sua visão de mercado e a sua experiência na área de logística, segmento em que a empresa atua.

"Respondendo a sua questão, os investidores trouxeram para a empresa toda essa visão da administração, visão comercial e todo esse networking de mercado, tanto de clientes quanto de investidor".

O entrevistado da empresa "C" enxerga que a maior contribuição por parte do investidor-anjo veio em forma de capital humano, uma vez que 0 investidor assumiu a administração da empresa e pode passar toda sua 
experiência no campo da gestão. Ele revelou que a busca/escolha de um investidor já levava em consideração a sua capacidade de participar da gestão da empresa, assumindo a função de administrador do negócio, uma vez que os sócios não dispunham de tempo para se dedicar integralmente às atividades e não detinham experiência no campo da gestão.

"No nosso caso, o investidor-anjo também se tornou CEO da empresa, era um segundo objetivo nosso quando a gente decidiu buscar esse investidor anjo, era contratar uma pessoa pra se tornar o cabeça da Cia, porque no caso eu, que era o fundador, não tinha tempo disponível integral para a empresa e no momento achamos que era importante ter uma pessoa com dedicação maior e a decisão foi contratar um CEO para trabalhar e esse investidor anjo também se tornou um CEO da Cia."

Segundo o entrevistado da empresa "D", os investidores-anjos não estavam presentes na operação da empresa, no entanto contribuíam com a confiança e a autonomia oferecida, participando das decisões mais estratégicas para a empresa.

"Eles não ajudavam na operação, eles falavam pra gente que ninguém entendia mais do nosso business do que os empreendedores que viviam 24 horas por dia trabalhando com isso. 0 que eles ajudavam era na área mais high level, a parte mais estratégica."

$O$ entrevistado $E$ ressaltou que, de forma geral, os investidores participavam muito pouco da rotina da empresa. Segundo ele, a gestão da empresa e o desempenho das tarefas no dia-a-dia eram desempenhados por ele e por seus sócios, os fundadores da empresa.

"Os investidores sempre participaram pouco da empresa, eles sempre deixaram a operação comigo e com meu sócio. Eles participam muito pouco mesmo e quando participam é mais em questões grandes".

\section{Conclusão}

Durante as entrevistas observou-se que o envolvimento dos investidores não dependia exclusivamente de sua vontade, mas também dos empreendedores do negócio. Com o relato dos entrevistados observou-se que alguns investidores optam por ter uma participação mais significativa no negócio, assumindo a função de administradores e influenciando de forma direta na gestão das empresas, enquanto outros, optam por confiar a gestão das empresas aos empreendedores.

As entrevistas também permitiram a identificação de composições diferentes para os investimentos. Ao entrar em detalhes sobre as características dos investidores-anjos e da forma como o investimento ocorreu alguns entrevistados afirmaram ter recebido o investimento de um grupo de investidores, enquanto outros revelaram que receberam o investimento de investidores individuais.

Em relação ao networking, pode-se observar que os investidores, de forma geral, contribuíram de forma modesta com a ampliação da rede de contatos das empresas.

Sob o ponto de vista financeiro, os investimentos se mostraram importantes para as empresas, sobretudo, com a implementação de mudanças em seus modelos de negócio, com o desenvolvimento de novos produtos e o redirecionamento de mercado.

Em termos de governança, constatou-se que a contribuição dos investidores foi tímida. Em geral, os investidores influenciaram de forma positiva com a exigência de relatórios financeiros melhor estruturados, na melhoria de alguns processos ou até mesmo causando uma mudança de postura dos próprios empreendedores, no entanto, esta é uma influência que se pode considerar ainda pequena.

Alguns investidores, conforme apresentado na seção anterior, assumiram posições importantes na administração da empresa e, a partir do exercício destas funções e do conhecimento técnico que dispunham, puderam influenciar de forma direta no desempenho das empresas. Outros investidores, até mesmo por suas características, não participaram de forma ativa da gestão das empresas, mas ofereceram aos empreendedores apoio em outros campos, o que influencia de forma indireta no desempenho das empresas. 
Ao analisar os resultados obtidos foi possível observar que os investidores-anjos contribuíram de forma mais significativa com o suporte financeiro (aporte de capital) e, colocando à disposição da empresa o seu conhecimento técnico.

Em estudos futuros é importante sejam feitas novas análises a respeito da participação dos investidoresanjos na etapa de pós-investimento, com a realização de levantamentos quantitativos e o tratamento estatístico destes dados para obtenção de conclusões mais representativas a cerva da contribuição destes investidores.

\section{Referências}

ABDI - Agência Brasileira de Desenvolvimento Industrial . A indústria de Private Equity e Venture Capital. $2^{\circ}$ Censo Brasileiro. Março/2011.

ARDICHVILI, A.; CARDOZO, R.; TUNE, K.; REINACH, J. (2002). The role of Angel Investors in the Assembly of non-financial resources of New Ventures: Conceptual Framework and Empirical Evidence. Journal of Enterprising Culture, 10 (1), pp. 39-65.

AVDEITCHIKOVA, Sofia (2008). On the structure of the informal venture capital market in Sweden: developing investment roles. Venture Capital, 10, pp. 55-85.

BOTELHO, A. J. J.; DIDIER, D.; RODRIGUEZ, M. V. R. (2006). Impulsionando o Take-off da Inovação no Brasil: O Investidor Anjo. ENANPAD 2006. 23 à 27 de setembro de 2006. Salvador BA.

CARIS, Jean L. Relacionamento investidor informal/empreendedor no Brasil: estudo de casos. 156F. Dissertação de mestrado - Programa de Pós-Graduação em Administração, Instituto COPPEAD de Administração, Universidade Federal do Rio de Janeiro, 2006.

COLLEWAERT, Veroniek; FASSIN, Yves. (2009). Conflicts between entrepreneurs and investors: the impact of perceived unethical behavior. Small Business Economics, vol. 40, pp. 635-649.

CUMMING, Douglas. (2008). Contracts and Exits in Venture Capital Finance. The Review of Financial Studies, vol. 21, no. 5 .

DE CLERCQ, D.; FRIED, V.H. (2005). Executive forum: how entrepreneurial company performance can be improved through venture capitalists' communication and commitment. Venture Capital: An International Journal of Entrepreneurial Finance, 7, pp. 285-294.

DE LIMA, Leonardo R. 0 modelo brasileiro de private equity e venture capital. 2006. 147f. Dissertação de mestrado - Faculdade de Economia, Administração e Contabilidade, Universidade de São Paulo, São Paulo, 2006.

DE NOBLE, A. F. (2001). "Review essay: raising finance from business angels". Venture Capital: An International Journal of Entrepreneurship Finance, vol. 3, no. 4, pp.359-367.

FILI, A.; GRÜNBERG, J. (2014). Business angel post-investment activities: a multi-level review. Journal of Management Governance.

FREAR, J., SOHL, J. and WETZEL, W. (2002). Angels on Angels: financing technologybased ventures - an historical perspective. Venture Capital, vol 4, n 4, 275-287 pp.

FREITAS, J.; CALVOSA, M. (2008). O Investimento Anjo com Alavancador da Atividade Empreendedora no Brasil. XI Seminários em Administração - USP, 2008, São Paulo. XI SEMEAD.

HARDING, R.; COWLING, M. (2006). Points of view: assessing the scale of the equity gap. Journal of Small Businesses and Enterprise Development, vol. 13, no. 1, pp. 115-132.

KELLY, P.; HAY, M. (2003). Business angel contracts: the influence of context. Venture Capital, 5 (4), pp. 287-312.

LEE \& CORREA (2004). Promoting entrepreneurship and innovative SMEs in a global economy: towards a more responsible and inclusive globalization. In: 2nd OECD Conference of Ministers responsible for 
small and medium-sized enterprises (SMEs). Istanbul, Turkey 3-5 June.

MACTH, Stephanie A. (2006). The Post-Investment Impact of Business Angels upon their Investee Companies. Institute for Small Business \& Entrepreneurship, (November), pp. 1-15.

MACTH, Stephanie A. (2011). Inexpert Business Angels: How Even Investors with 'Nothing to Add' Can Add Value. Strategic Change: Briefings in Entrepreneurial Finance., vol. 20, pp.269-278.

MACTH, Stephanie A.; Robinson, John (2009). Do business angels benefit their investee companies? International Journal of Entrepreneurial Behaviour \& Research, vol. 15, no. 2, pp. $187-208$.

MACTH, Stephanie A.; WEATHERSTON, J. (2011). Towards a theory of business angels' post-investment: a resource-based approach. Regional Frontiers of Entrepreneurship Research. Swinburne University of Technology. Melbourne. pp. 87-101.

MADILL, J.; HAINES, G.; RIDING, A. (2005). The role of angels in technology SMEs: a link to venture capital. International Journal of Entrepreneurial Finance, 7 (2), pp. 107-129.

MASON, Colin M.; HARRISON, R. T. (2002). Is it worth it? The rates of return from informal venture capital investments. Journal of Business Venturing, vol. 17, pp. 211-236.

MAXWELL, Andrew L.; JEFFREY, Scott A.; LÉVESQUE, M. (2011). Business angel early stage decision making. Journal of Business Venturing, vol. 26, pp. 212-225.

PARHANKANGAS, A.; EHRLICH, M. (2014). How entrepreneurs seduce business angels: An impression management approach. Journal of Business Venturing, vol. 29, pp.543-564.

PAVANI, Cláudia. 0 capital de risco no Brasil: Conceito, evolução e perspectivas. Rio de Janeiro: Editora E-papers, 2003.

PRESTON, S. L. (2004). Angel Investment Groups, Networks, and Funds: A Guidebook to Developing the Right Angel Organization for Your Community. The Ewing Marion Kauffman Foundation.

RAMADANI, Veland. (2009). Business angels: who they really are. Strategic Change, vol. 18, pp. 249258.

RIECHE, Fernando; DOS SANTOS, Leonardo (2006). Investimento em pequenas e médias empresas com elevado potencial de crescimento - critérios de seleção dos capitalistas de risco. Revista do BNDES, Rio de Janeiro, v.13, n. 26, p.89-114.

SANTOS, S. A. Empreendedorismo de Base Tecnológica: evolução e trajetória. Maringá: UNICORPORE, 2005.

SOHL, J. E. (2002). The Private Equity Market Gyrations: What Has Been Learned? Venture Capital: An International Journal of Entrepreneurial Finance: v 4, n.4, p. 267-274.

SOHL, J. E. (2003). The private equity market in the USA: Lessons from volatility. Venture Capital, 5, 29$46 \mathrm{pp}$.

SOHL, J. E. (2007). The angel Investor Market in 2006: The Angel Market continues steady growth. Center of Venture Research.

SPINA, Cassio. Investidor Anjo. Guia Prático Para Empreendedores e Investidores. São Paulo: nVersos, 2011. 176p.

VANACKER, T.; COLLEWAERT, V.; PAELEMAN, I. (2013). The Relationship between Slack Resources and the Performance of Entrepreneurial Firms: The Role of Venture Capital and Angel Investors. Journal of Management Studies, Vol. 50, No 6.

VAN OSNABRUGGE, M.; Robinson, R. (2000). Angel investing: matching start-ups funds with start-up companies. Jossey-Bass, San Francisco. 